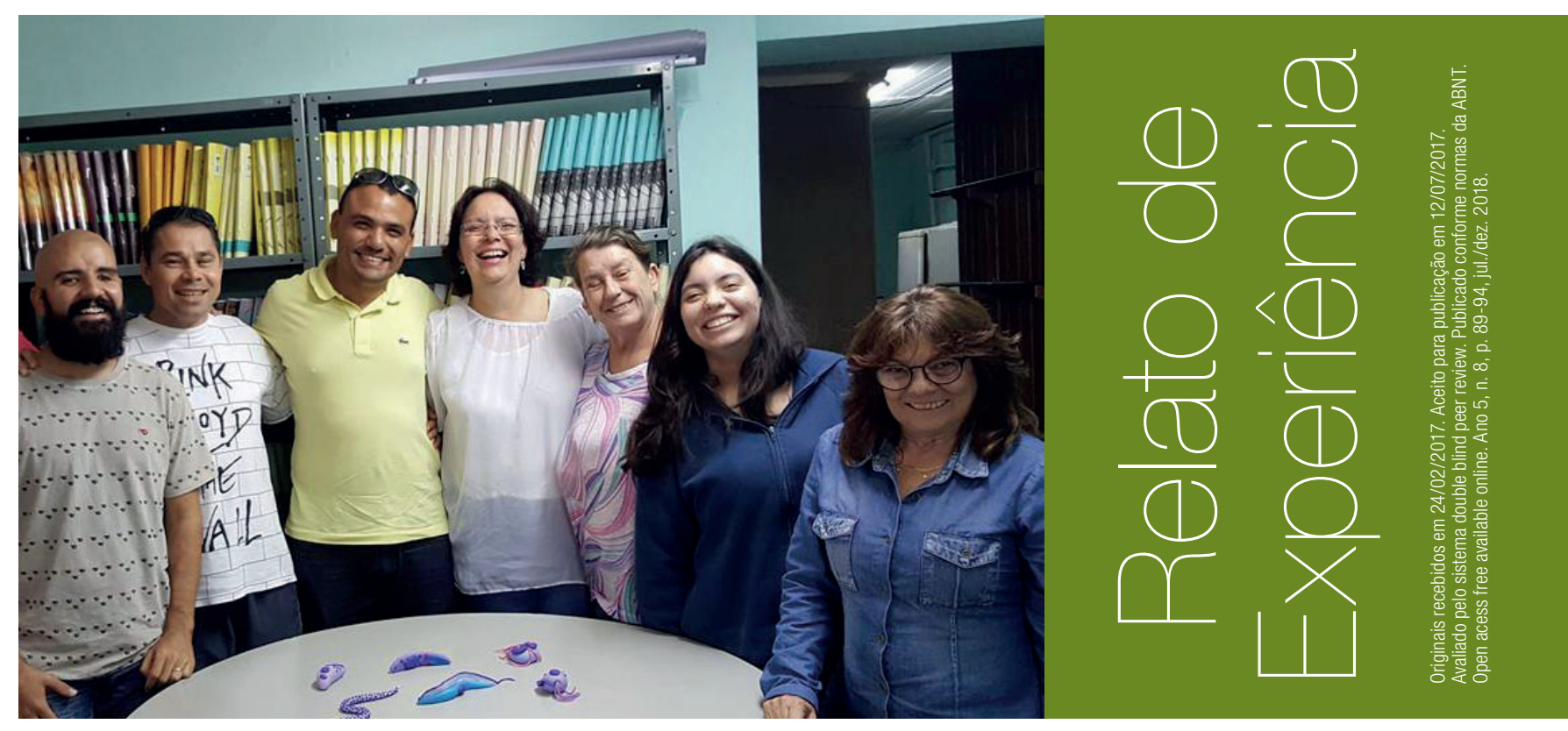

\title{
Parasitos na sua mão: uma proposta de inclusão para o ensino e promoção da saúde
}

\author{
Marcelo Alberto Elias ${ }^{1}$ - marcelo.elias@ifsc.edu.br \\ Hagar Lara Tiburcio de Oliveira² - hagar.lara@ifsc.edu.br
}

\section{RESUMO}

A temática da inclusão nas escolas tem promovido um movimento bastante significativo entre os educadores visando atender às necessidades especiais dos alunos. Dentro dessa perspectiva, 0 projeto de extensão buscou promover educação à saúde de alunos com necessidades visuais (cegos ou com baixa visão) abordando doenças parasitárias bastante comuns em países tropicais como 0 Brasil de uma forma inclusiva. A proposta foi confeccionar modelos didáticos de parasitos com biscuit em escalas macroscópicas. 0 trabalho foi realizado no segundo semestre de 2016 no Instituto Federal de Santa Catarina (IFSC) Câmpus Gaspar e a Sociedade Cultural Amigos do Centro Braile (ACBB). Foram confeccionados 12 modelos de parasitos em duplicata e duas apostilas informativas em braile. 0 projeto foi financiado pelo Edital 02/2016 da PROEX e garantiu a produção de materiais inclusivos, que poderão ser utilizados no próprio câmpus e também em outras instituições de ensino que ofertem educação básica.

\section{PALAVRAS-CHAVE}

Inclusão. Parasitologia. Modelos Didáticos. Deficiência Visual.

\section{ABSTRACT}

The theme of inclusion in schools has promoted a significant movement among educators to meet the special needs of students, within this perspective the present extension project sought to promote health education for students with visual needs (blind or with low vision) addressing diseases Parasitic diseases common in tropical countries like Brazil in an inclusive way. In this

\footnotetext{
1 Mestre em biologia das interações Orgânicas e Professor do Ensino Básico, Técnico e Tecnológico - IFSC Câmpus Gaspar

2 Professora de Apoio de Educação Especial - IFSC Câmpus Gaspar.
} 
way the proposal was to make didactic models in biscuit of parasites in macroscopic scales. The work was carried out within the second half of 2016 at the Federal Institute of Santa Catarina - IFSC/ Gaspar in partnership with the Cultural Society Friends of the Braille Center - ACBB. Finally, 12 models were made in duplicate, totaling 24 models of parasites and 2 informative handouts in braille. The project was financed by the PROEX 02/2016 announcement and guaranteed the production of inclusive materials that could be used both on the câmpus itself and also be provided to basic education schools when necessary.on the subject in practice, recognized the value of art and education as a field of knowledge, experimentation and exchange of experiences.

\section{KEYWORDS}

Inclusion. Parasitology. Didactic Models. Visual impairment.

\section{Relato de experiência}

A educação inclusiva busca garantir que todos os alunos aprendam juntos, isto é, mesmo em casos específicos todos têm o direito de estarem matriculados no ensino regular. Nesse sentido, com vistas a valorizar a diversidade, a escola deve ser acolhedora e integrar esses alunos oportunizando 0 acesso igualitário em todos os níveis culturais.

Nessas circunstâncias, para que se efetive a aprendizagem de alunos com deficiência em espaços regulares de educação, torna-se necessário um trabalho articulado entre escola e Atendimento Educacional Especializado (AEE), que é definido legalmente como "o conjunto de atividades e recursos pedagógicos e de acessibilidade, organizados institucionalmente, prestado de forma complementar ou suplementar à formação dos estudantes [...]"(BRASIL, 2013, p.2).

As intervenções do AEE variam conforme as especificidades da(s) deficiência(s) apresentada(s) pelo aluno. No caso da cegueira, o trabalho torna-se especialmente desafiador quando se trata do ensino de ciências. A literatura da área aponta a ocorrência de dois tipos de cegueira: a congênita e a adquirida (adventícia). A cegueira congênita corresponde à ausência da visão manifestada durante os primeiros anos de vida, e a adquirida, à perda de visão ocorrida repentinamente, comumente ocasionada por causas orgânicas ou acidentais (SÁ; SIMÃO, 2010)

As autoras Sá e Simão (2010) relatam que durante uma pesquisa realizada no Curso de Formação de Professores de Atendimento Educacional Especializado, realizado em 2008, cerca de mais de 400 de um universo de 1800, tendo representantes de 161 municípios brasileiros - demonstraram concepções estereotipadas acerca da cegueira e do trabalho pedagógico voltado para os alunos cegos. Essa realidade reforça a importância de se ter um conhecimento das especificidades dessa clientela para a promoção de um atendimento efetivamente inclusivo.

Ressalta-se ainda que a educação inclusiva depende tanto de matrículas no ensino regular quanto dos recursos pedagógicos para 0 acesso ao conhecimento. Além, é claro de todo o subsídio para professores, escolas e família.

Diante disso, utilizar recursos didáticos acessíveis apenas para as pessoas que enxergam, como 0 microscópio, por exemplo, é fundamental que o professor tenha um olhar sensivel às possibilidades de adequação para que o aluno cego também possa participar da aula e adquirir os conceitos, como os alunos que veem.

Assim aprovado pelo Edital número 02/2016 Aproex do Instituto Federal de Santa Catarina, surgiu o projeto "Parasito na sua mão", com uma proposta integradora de aproximar conceitos microscópicos até então inacessíveis aos deficientes visuais, palpáveis de maneira mais real possivel, visando melhorar o ensino de biologia para esse público.

0 projeto foi realizado no câmpus da cidade de Gaspar-SC durante o segundo semestre de 2016, mobilizando o Núcleo de Apoio a Pessoas com Necessidades Especiais (NAPNE). A temática escolhida foi parasitologia, pois, como ela mesma pode ser observada apenas em microscópios, 0 que acaba excluindo toda e qualquer participação dos cegos em tais atividades. 
Outro fator motivador dessa escolha foi a possibilidade de promover a conscientização sobre doenças parasitárias, que são infelizmente comuns em países tropicais como 0 Brasil. Esse assunto é muito abordado geralmente no sétimo ano das séries finais do ensino fundamental II e retorna mais aprofundado no segundo ano do ensino médio.

A proposta central do projeto foi a utilização de massa de modelagem do tipo biscuit para confecção dos parasitos. Inicialmente, a bolsista envolvida no projeto fez um levantamento das principais características dos parasitos a serem confeccionados com o professor orientador, visando sempre evidenciar aquelas mais marcantes. Esse trabalho foi realizado a partir de pesquisa em atlas de parasitologia, que oferecem várias imagens diferentes de um mesmo parasito.

Após a definição das características, iniciou-se 0 trabalho de confecção dos primeiros modelos.
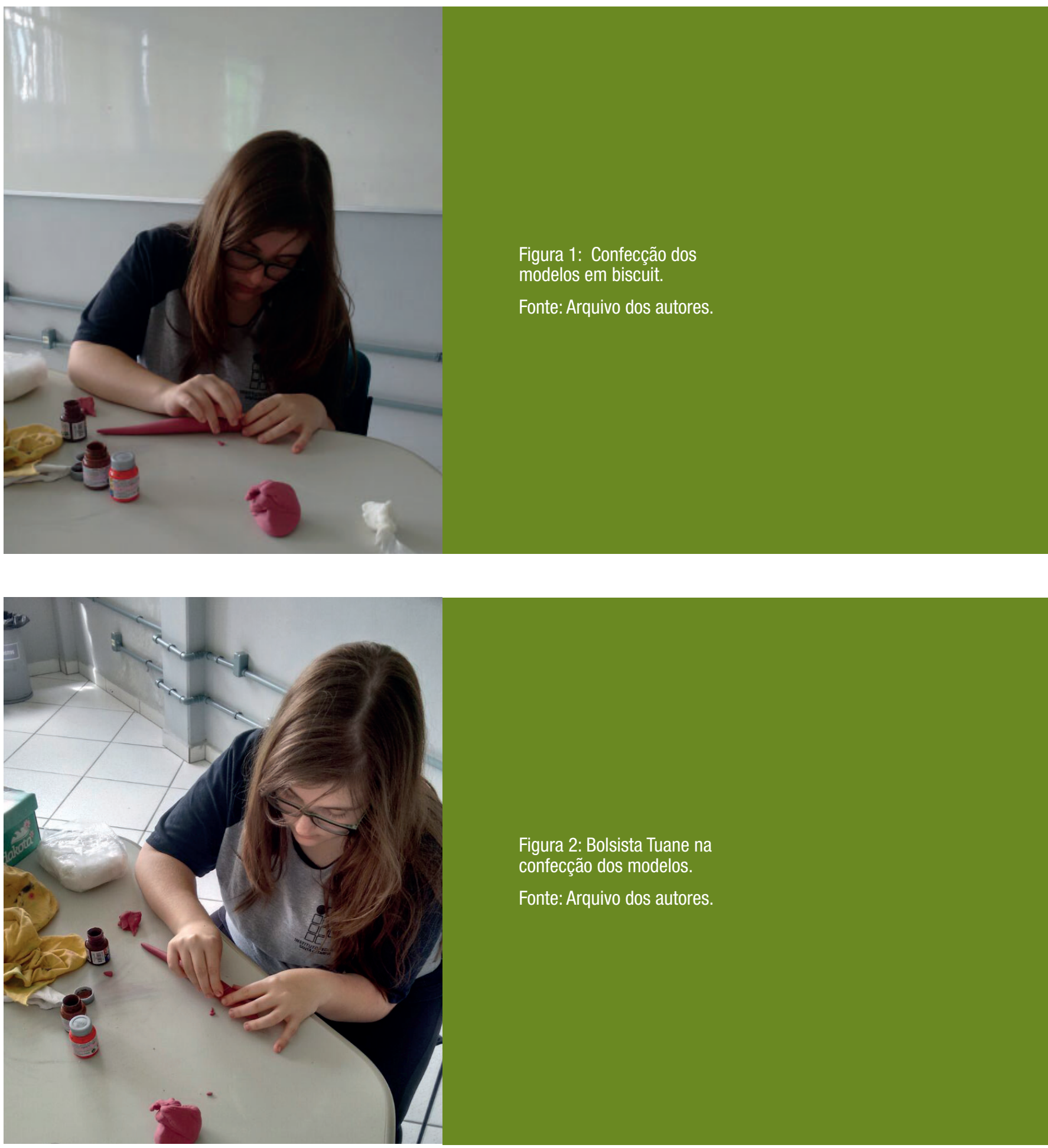

Figura 2: Bolsista Tuane na confecção dos modelos.

Fonte: Arquivo dos autores. 
Figura 3: Modelos em biscuit em confecção.

Fonte: Arquivo dos autores.

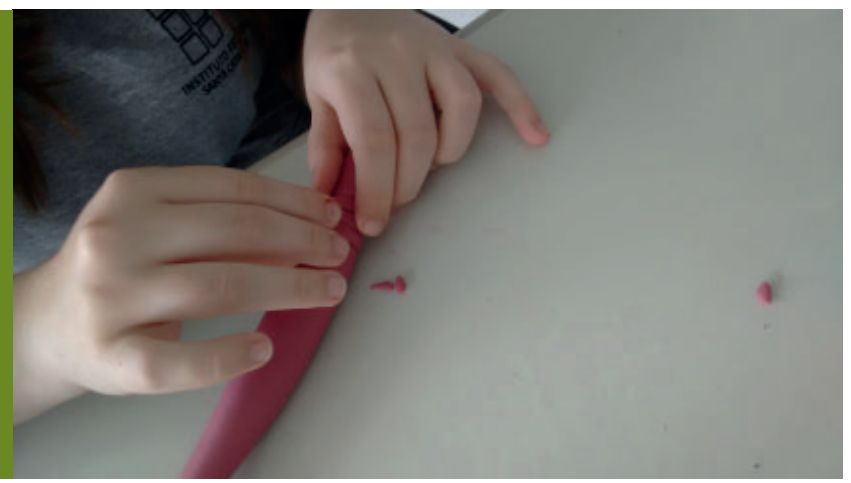

Esses modelos iniciais foram avaliados pelo professor orientador e, na sequência, passaram por uma avaliação prática pela comunidade cega, representada pela Sociedade Cultural Amigos do Centro Braile de Blumenau (ACBB). Nessa etapa, foram feitas contribuições de melhorias para os modelos. A equipe executora do trabalho descrevia as características, e os avaliadores cegos verificavam se era realmente possível "sentir" o que estava sendo proposto. A avaliação aconteceu na sede da ACBB, e todas as sugestões foram anotadas para melhoria dos modelos.

Figura 4: Membros da ACBB avaliando os primeiros modelos.

Fonte: Arquivo dos autores.

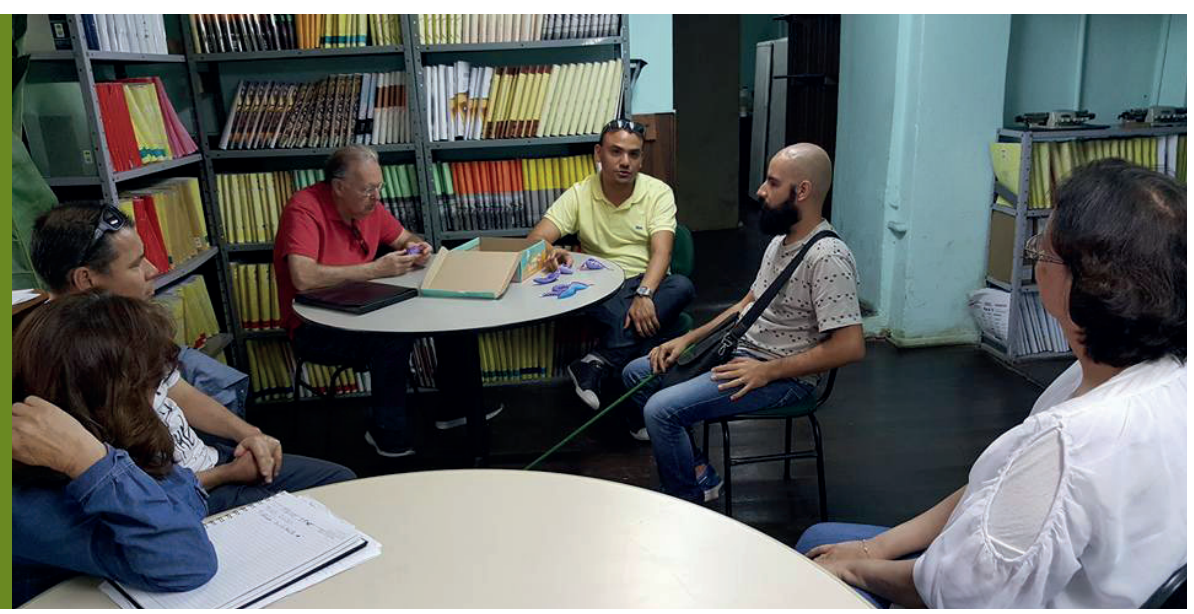

Figura 5: Membra da ACBB avaliando modelo.

Fonte: Arquivo dos autores.

Após as melhorias necessárias, os 12 modelos foram finalizados, sempre em duplicata, produzindo dois conjuntos de 12 peças: um para o uso do câmpus e outro para ser doado à ACBB. Ressalta-se que o projeto objetivava criar modelos para aulas e atividades de extensão do IFSC e fornecer à comunidade cega, como material para uso em palestras, oficinas e apoio ao ensino especial. Ao término da confecção, cada parasito foi alocado em uma caixa com sua respectiva identificação em braille. Vale ressaltar que os modelos são todos coloridos, a fim de se atingir também as pessoas de baixa visão. 


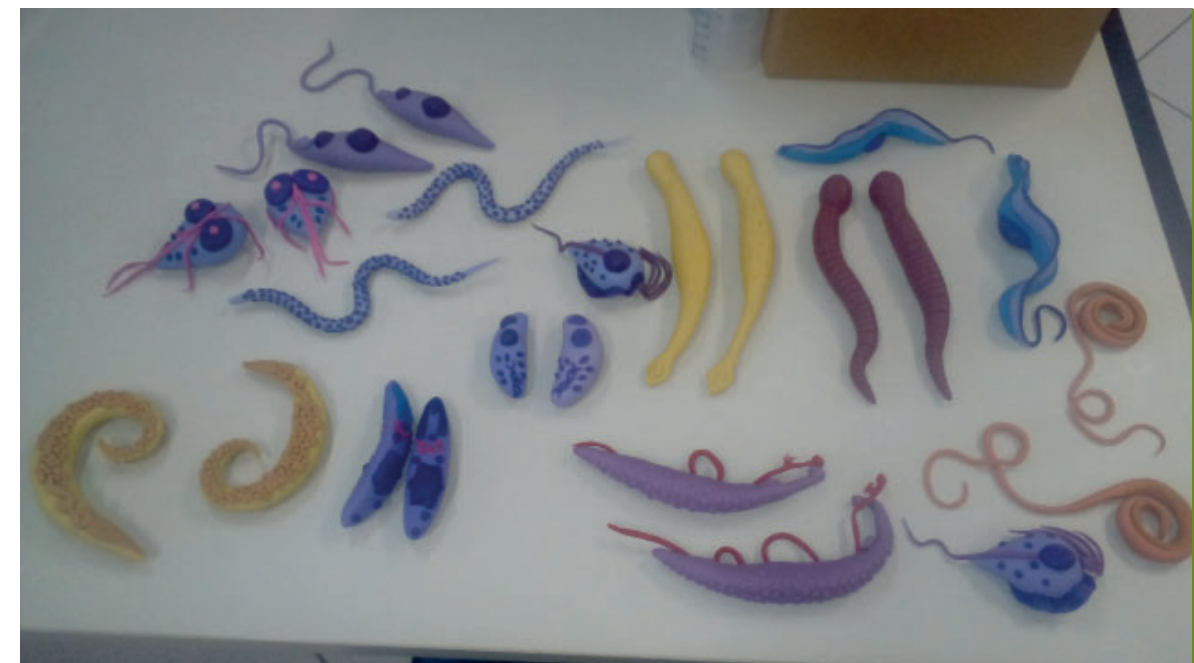

Figura 6: Modelos de

parasitos em duplicata. Foram confeccionados os parasitos:

Ancylostoma duodenale, Larva

migrans, Trichuris trichiura,

Enterobius vermicularis,

Schistosoma sp., Trypanosoma cruzi, Toxoplasma gondii,

Giardia lamblia, Plasmodium

$\mathrm{sp}$, Wuchereria bancrofti,

Leishmania sp. e Trichomonas vaginalis.

Fonte: Arquivo dos autores.

Foi elaborada ainda uma cartilha explicativa sobre os parasitos confeccionados. A linguagem utilizada foi simples, porém científica. Impressa também em braille, a cartilha contém as informações básicas, a escala de aumento e o conjunto dos 12 modelos dos parasitos.

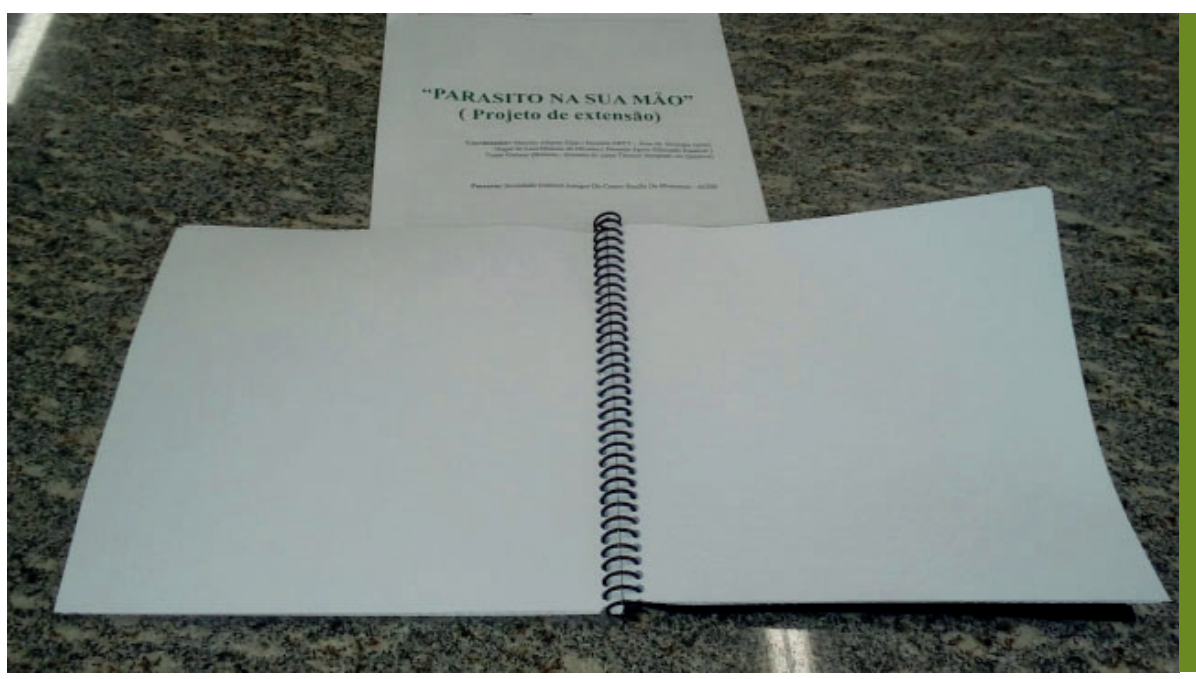

Figura 7: Cartilha em braile.

Fonte: Arquivo dos autores.

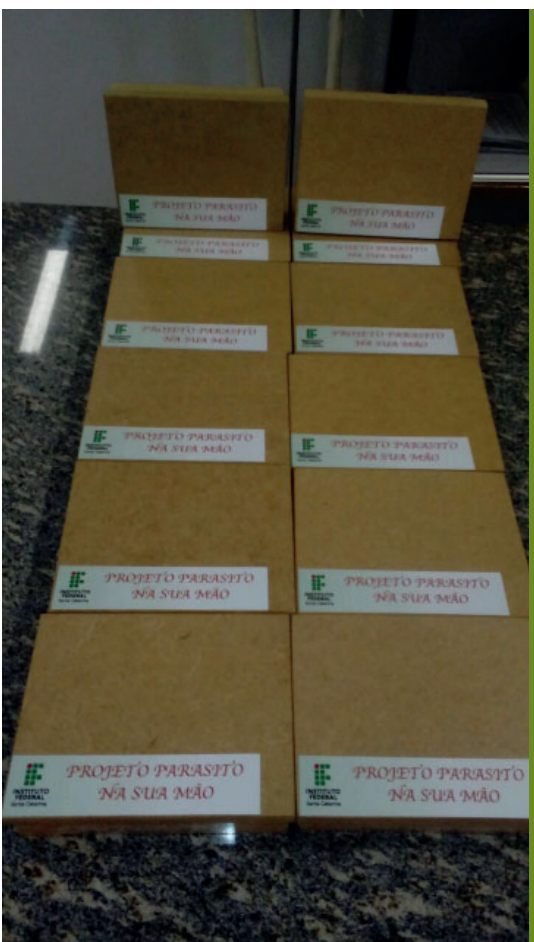

Figura 8: Caixas individuais com parasitos.

Fonte: Arquivo dos autores. 
Figura 9: Parceria ACBB e IFSC.

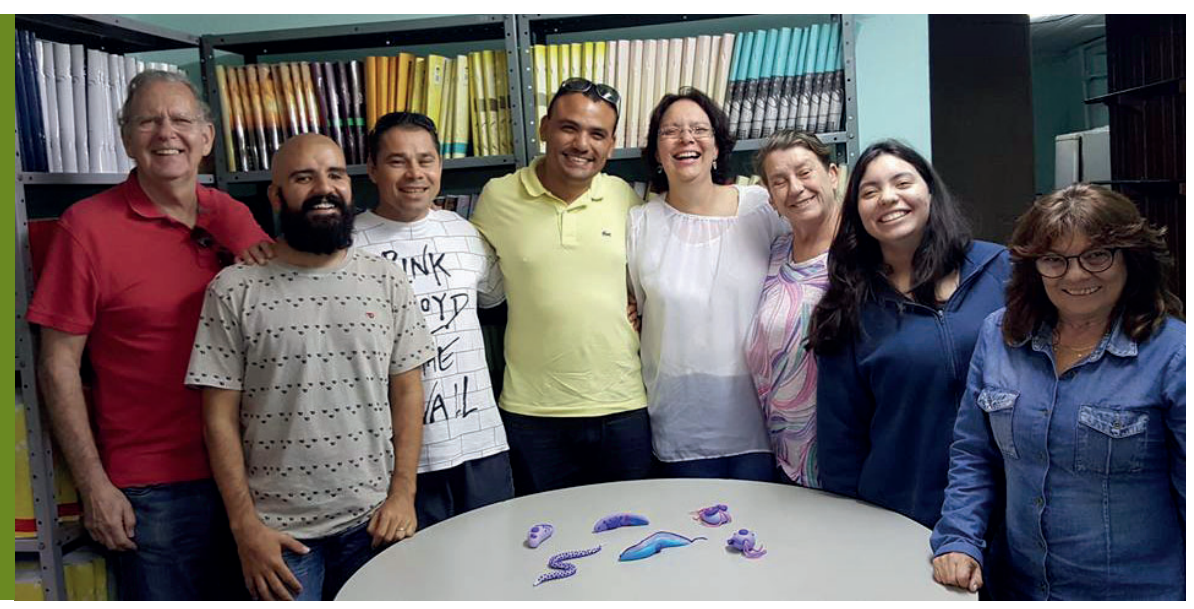

Embora a confecção dos modelos exija muita paciência e delicadeza, não houve, na execução do trabalho, dificuldades capazes de desanimar ou impedir novas ideias. Na mesma direção, é importante ressaltar que para sse tipo de ação é fundamental o envolvimento do público-alvo. Sem participação dos cegos, a validação dos modelos poderia ficar comprometida.

A professora de educação especial Hagar, representante do NAPNE atualmente envolvida no projeto, apresentou o seguinte relato:

"Foi uma experiência muito marcante participar desse projeto, já que não havia trabalhado com cegos antes, entusiasmou-me a fazer um curso de Braille e vivências em audiodescrição no Centro Braille de Blumenau, onde pude vivenciar um sentimento de empatia e sentir as dificuldades que as pessoas cegas sentem seja na locomoção ou na acessibilidade. No curso além de aprender a utilizar as tecnologias assistivas como reglete e punção para escrever em Braille, também pude conhecer e manipular o sistema Dos-vox e fazer locomoção com vendas nos olhos utilizando a bengala e depois uma pessoa guia."

Os modelos confeccionados estão disponíveis no laboratório de biologia do câmpus podendo ser usados pelos próprios professores e também emprestados a outros professores da rede de educação básica do município. Já os modelos da ACBB ficaram na sede da entidade para uso em aulas de ciências e em formações de professores, suprindo assim a carência de material inclusivo existente na própria sede.

Após o término do projeto os modelos já foram usados em aulas e expostos na semana nacional dos museus e em atividades inclusivas no câmpus, promovendo um grande movimento por parte de alunos, professores e comunidade escolar no sentido do pensamento inclusivo na escola.

Verifica-se, assim, que pequenas ideias, materializadas em atitudes concretas, podem fazer toda a diferença. A escola é um ambiente muito criativo para tais ações, e devemos incentivar que elas aconteçam principalmente com parcerias envolvendo a comunidade externa. Por fim com 0 trabalho apresentado, foi possivel promover a inclusão, oferecer um modelo de material didático aos professores de ciências e biologia e contribuir com a promoção da saúde à pessoa com deficiência visual.

\section{Referências}

BRASIL. Orientação à atuação dos Centros de AEE, na perspectiva da educação inclusiva. Nota Técnica n 55. Brasília: MEC/SECADI/DPEE, 2013

SÁ, E.D.D.; SIMÃO, V.S. Alunos com cegueira. In: A educação especial na perspectiva da inclusão escolar: os alunos com deficiência visual: baixa visão e cegueira. Ministério da Educação: Secretaria de Educação Especial. Brasília, v.3, 2010. 